\title{
Use of a PEST calibrated Source Catchments model and regional water quality data to improve the predictive capacity of constituent load generation in the Torrens River Catchment
}

\author{
S. Thomas ${ }^{\text {a }}$, Y. He ${ }^{\text {a }}$, N. Fleming ${ }^{b}$ \\ ${ }^{a}$ Water Quality Branch, Environment Protection Authority, South Australia \\ ${ }^{b}$ Water Resources and Irrigated Crops, SA Research and Development Institute, South Australia \\ Email:shaun.thomas@epa.sa.gov.au
}

\begin{abstract}
Catchment models are useful decision support tools which simulate impacts of changes in a range of inputs on water quantity and quality issues. These issues are important to catchment managers for prioritising remediation on sub-catchments or landuses which contribute pollutants to receiving waters.

This paper describes use of the eWater "Source Catchments" model to simulate water flows, sediment and nutrient loads in the Torrens River catchments of the Mount Lofty Ranges Watershed in South Australia. Rainfall and landuse are used as primary factors leading to run-off and pollutant transport. The Torrens River is a fairly complex system and includes regulated and unregulated catchments, reservoir in-flows, transfers between reservoirs and inter-basin transfer from the Murray River. The hydrology of the Source Catchments model was calibrated with the model-independent parameter estimation program (PEST) to best simulate this complexity.
\end{abstract}

A range of data analysis approaches were also used to create surface and base flow constituent generation values for suspended solids, total nitrogen and total phosphorus for 12 landuse types. These values were generated from primary landuse as well as composite sampler load data from 16 catchments in the Adelaide and Mt Lofty Ranges region. Analysis of this local data; which spans more than 20 years at some locations; has generated locally relevant constituent data for major landuses in the Mt Lofty Ranges Watershed. This task was made easier through the use of eWater's "Water Quality Analyser" software tool.

Better characterisation of both hydrology and constituent generation has improved the predictive capacity of the Source Catchments model from previous versions, which were manually calibrated and used non-local constituent data. The predictive capacity total nitrogen and total phosphorus has significantly improved although there was still considerable uncertainty around the suspended solids loads. The improved model will be used to target management actions and simulate impacts of strategic policy initiatives to reduce the pollutant loads to drinking water reservoirs in the Mount Lofty Ranges.

Keywords: catchment modelling; PEST; Source Catchments; water quality 


\section{INTRODUCTION}

Within Australia the impacts of elevated nutrients (nitrogen and phosphorus) and suspended sediments leading to eutrophication and smothering of aquatic ecosystems are ongoing issues for natural resource management bodies and water authorities. These constituents can contribute to algal blooms in reservoirs and increase water treatment requirements and associated costs. The constituents are exported from a range of land uses within catchments, including broadacre and irrigated agriculture, intensive horticulture, rural living, plantation forests, native vegetation and urban environments.

The catchments of the Mount Lofty Ranges (MLR) are a water resource which is crucial to the well-being of the people of Adelaide. There are seven reservoirs on rivers and streams of the MLR which harvest the relatively high rainfall and supply Adelaide with drinking water. This drinking water is supplemented with water diverted from the River Murray. In addition to the harvesting of drinking water the MLR are used and valued for a range of different purposes (e.g. irrigation of perennial and annual horticulture, stock and domestic use). These multiple uses place pressure on the water resource and can have significant impacts on water quality.

A range of modelling approaches has been used to model the export of these constituents within catchments. These models have investigated the impacts of land use and changes in land management, relative benefit of on-ground works, changes to government policy and impacts of climate change. Modelling approaches range from an annual nutrient loading per land use (eg. CMSS), concentration generation rates per land use (e.g., EMSS), to more complex integrated catchment models (eg. Source Catchments) (Barlow et al. 2009).

There are several challenges to overcome before producing a model which can simulate nutrient and sediment export at the catchment scale. These include the availability and quality of climate and hydrological data, the method to model generation and transport of constituents within the catchment and the approach to hydrological calibration. The two main challenges that are investigated in this paper are a) comparison between an automated hydrological calibration and a manual calibration; and b) comparison between constituent generation rates for a range of landuses based on either analysis of local data from regional composite samplers or constituent generation rates taken from literature.

In this paper, we use the model-independent parameter estimation program - PEST (Doherty, 2010) to systematically calibrate the hydrology of a Source Catchments model of the Torrens River within the MLR watershed. In addition we analysed water quality data from a network of flow weighted composite samplers in the MLR and surrounding region. We used this output to generate local constituent generation data for 11 major landuses. This calibrated model is being used to examine a range of management scenarios that will provide key inputs into the development of a regional watershed water quality improvement plan.

\section{STUDY AREA}

The Torrens catchment as seen in Figure 1 is within the central region of the MLR, and the portion of the catchment within the watershed is approximately $331 \mathrm{~km}^{2}$. The headwaters of the catchment are characterised by a landscape of low relief related to the high summit plain. The landscape grades to rolling hills nearer the middle of the catchment and the west is dominated by the steepsided, rocky valley of the Torrens Gorge (Twidale et al. 1976). The Torrens catchment contains two reservoirs - Millbrook and Kangaroo Creek. Water can be diverted from the

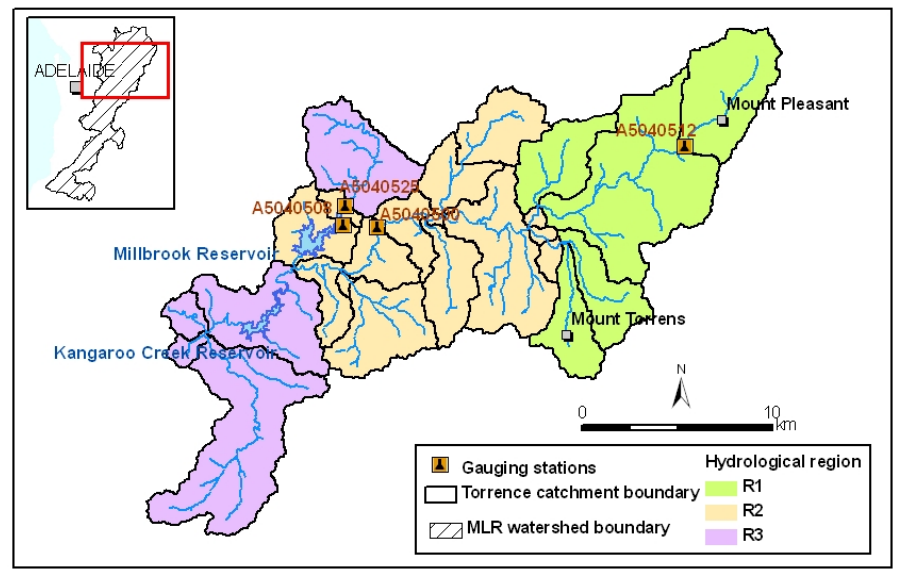

Figure 1. Location of gauging stations and reservoirs within the sub-catchments of the Torrens River catchment 
main channel to Millbrook Reservoir via the Gumeracha diversion weir, or flow directly through to Kangaroo Creek Reservoir downstream of the weir. The catchment also receives River Murray transfers via the Mannum-Adelaide pipeline, which releases water downstream of Mount Pleasant or Birdwood (Bradley et al. 2007).

The major land use in the Torrens catchment is grazing, comprising approximately $52 \%$ of the area. Conservation accounts for approximately $21 \%$ of land use with the remaining landuses comprising plantation forestry, horticulture and urban environments. Annual rainfall is around $680 \mathrm{~mm}$ across the catchment.

The study area contains four stream gauging stations, where daily flow has been measured. Water quality data has been measured through flow weighted composite samplers at two of the gauging stations although one of these records the regulated transfer between Gumeracha weir and Millbrook Reservoir. Most of the gauging stations have data from the 1970's although good quality data for the River Murray transfers is only available from 1993 to current day.

\section{MATERIALS AND METHODS}

\subsection{Overview of modelling approach}

A water quantity and quality model was developed for the Torrens catchments using eWater Source Catchments modelling software (http://www.toolkit.net.au/tools/source-catchments). Source Catchments has been developed for Australian conditions and enables the user to create models with relative complexity when limited data is available. The Torrens Source Catchments model was built with 25 subcatchments with runoff and pollutant generation modelled on a daily time step. There were 13 functional units (FUs) of which 2 related to water bodies, which are based on landuses derived from 2008 landuse data supplied by the Department of Environment and Natural Resources.

The SimHyd rainfall-runoff model (Chiew et al. 2002) was applied to describe the daily and monthly baseflow and streamflow in the Torrens catchment. The hydrological model was calibrated using two different approaches. One is called the Rainfall Runoff Library software (RRL) (Podger, 2004). Calibration using the RRL is essentially adjustment of one parameter at a time. A selection of optimising algorithms is available, and also of objective functions to assess fit of the model. The effect of changing each parameter is also shown the visual fit of a chart of simulated vs observed flow data. WBM (2006) calibrated the SimHyd values using RRL against the observed flow data sourced from the Department for Water (DFW) over the period of 1978 to 2003. The calibrated results are shown in Table 1.

The other method used an independent Parameter Estimation program (PEST), a program which optimises specified parameters according to defined objective functions, generally Nash-Sutcliffe function (daily and monthly flows) and modelled vs observed flow volumes. The numerical limits of parameters to be optimised are set, as are the increments of change for each parameter. End-of-run values are set for the rate of improvement in objective functions with changes in variables, that is, the incremental improvement in model fit with each successive run. The maximum number of iterations in a PEST run is also set, in case a satisfactory solution is not found. A single PEST run may optimise multiple parameters at multiple gauges simultaneously. The process of PEST calibration is detailed in Section 4.1.

Nutrient and sediment generation in Source Catchments was described for each landuse through the use of an event mean concentration (EMC) and dry weather concentration (DWC) for streamflow and baseflow conditions respectively. The nutrients represented were total nitrogen (TN) and total phosphorus (TP), and sediments were simulated as total suspended solids (TSS). Further details regarding the development of locally derived EMC and DWC values for each land use are discussed below.

\section{RESULTS AND DISCUSSION}

\subsection{Hydrological calibration}

Data was available from DFW for 4 streamflow gauges -2 unregulated catchments (5040512 and 5040525), one unregulated catchment (5040500) and one transfer point from Gumeracha weir to Millbrook reservoir (5040508). Interbasin transfer data obtained from SA Water was used from the two Murray River inflow points (Angas Creek and Mt Pleasant pumping stations). The model used SILO $5 \mathrm{~km}$ gridded data for both 
daily rainfall and daily areal evapotranspiration sourced from Queensland department of Natural Resources and Environment's SILO service. Three calibration regions were created from the catchment gauges (as seen in Figure 1), each region had up to 5 hydrologic response units (HRU). The overall calibration statistics are shown in Table 1 along with the PEST model calibration periods for each region. The RRL model was calibrated from $1978-2003$ for each region. The difference in calibration periods is due to the use of the available interbasin transfer data in the PEST model calibration. The Source Catchments model was calibrated with PEST over the entire data period, instead of having a calibration period and then a validation period. This unusual approach was taken because a significant drought in South Australia impacted the MLR for much of the late 1990's and most of the 2000s. There was no prolonged drought during the earlier recorded period. This disparity in climate would have biased both the calibration and validation results, so a single calibration period was used instead.

Table 1. Monthly Nash-Sutcliffe (NS) values for hydrologic calibration of Source Catchments models in the Torrens catchment using RRL and PEST.

\begin{tabular}{|c|c|c|c|c|c|}
\hline \multirow{2}{*}{ Catchment } & \multirow{2}{*}{ Gauge } & \multicolumn{2}{|c|}{ NS monthly (RRL model) } & \multirow{2}{*}{$\begin{array}{l}\text { NS monthly } \\
\text { (PEST model) }\end{array}$} & \multirow{2}{*}{$\begin{array}{c}\text { PEST model } \\
\text { calibration period }\end{array}$} \\
\hline & & calibration & verification & & \\
\hline Gumeracha & 5040500 & 0.63 & 0.29 & 0.7 & $1983-2008$ \\
\hline Kersbrook & 5040525 & - & - & 0.93 & $1989-2008$ \\
\hline Angas Ck & 5040512 & 0.69 & 0.82 & 0.94 & $1973-2008$ \\
\hline
\end{tabular}

Monthly NS values for the PEST model were higher than those for the RRL model. This is most likely because of the more rigorous optimisation provided by the PEST program. Gauge 5040500 had the lowest NS value, probably because of variation introduced by water transfer from Gumeracha weir (5040508) upstream of the gauge. Cumulative flow over the simulation period of 1993 - 2008 for gauges 5040525 and 5040512 is shown in Figure 2.
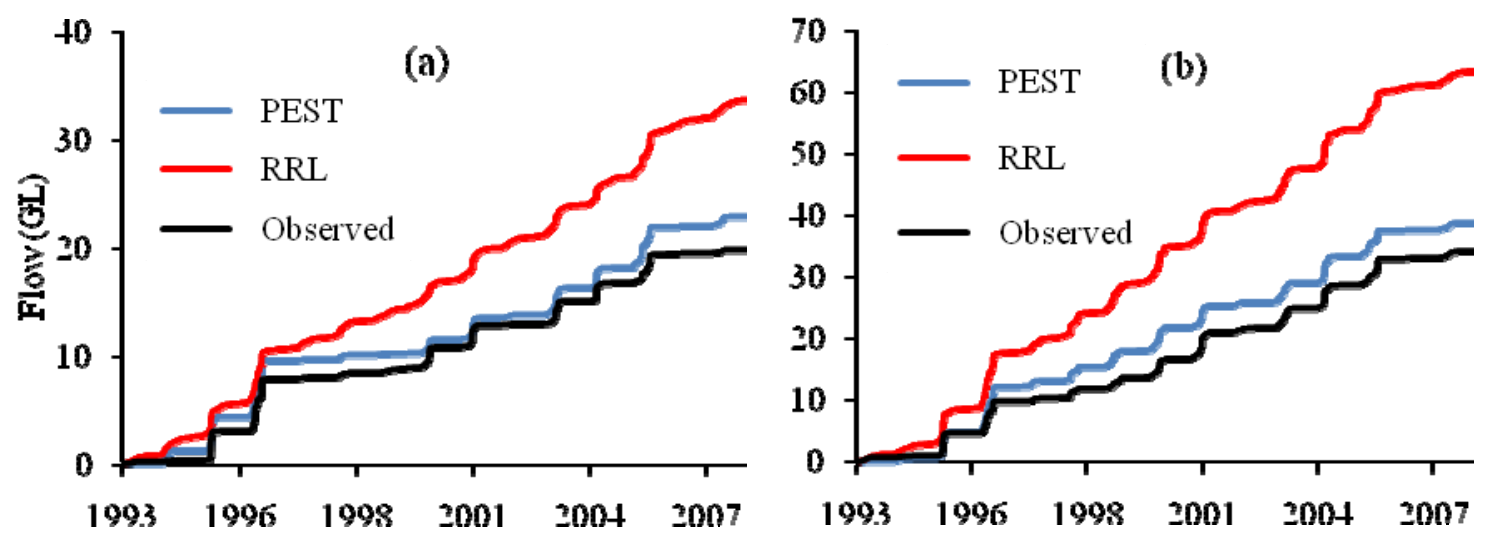

Figure 2. Cumulative flow plots showing relative performance of RRL and PEST calibrated models for the stream gauges (a) 5040512 and (b) 5040525

The PEST model predicted slightly higher flows than observed at site $5040512(10 \%)$ and 5040525 (16\%). The RRL model overestimated flow at both sites by $90 \%$ and $88 \%$, respectively.

\subsection{Constituent generation}

A popular constituent generation model in Source Catchments is the EMC/DWC model. The EMC is the flow-weighted average pollutant concentration over a storm event, while the DWC is the pollutant concentration measured during dry weather (i.e. baseflow). EMC and DWC can vary with land-use, soil type, slope, climate and management practices in the catchment area. The EMC and DWC values for the original MLR Source Catchments model (WBM, 2006) were developed from values in the Australian literature. New EMC and DWC values were calculated using data from a local network of flow-weighted composite samplers. The sites and analyses are described by Fleming et al. (2010). Briefly, a dataset was collated from flow-weighted composite samplers throughout the MLR. These were located at varying points in catchments, 
ranging from upper catchment (single land use) to major catchment outlets (multiple land uses). Previous and current EMC and DWC values are shown in Table 2, these values are an average constituent generation rate for these landuses throughout the MLR over the period with which the composite data was collated as such it does not capture variation in management practices. Some EMC values calculated for the MLR are comparable to those used previously. However, for many land uses the new EMCs differ considerably from those used previously. These differences are not surprising as the previous values were largely based on water quality monitoring of semi-tropical rivers

Table 2. EMCs and DWCs for TSS, TN, TP previously used in MLR Source Catchments model (normal font), and comparable values calculated from local data (bold font).

\begin{tabular}{lcccccc}
\hline \multirow{2}{*}{ Landuse } & \multicolumn{2}{c}{ TSS } & \multicolumn{2}{c}{ TN } & \multicolumn{2}{c}{ TP } \\
& EMC & DWC & EMC & $\begin{array}{c}\text { DWC } \\
\text { mg/L }\end{array}$ & EMC & DWC \\
\hline \multirow{2}{*}{ Conservation area } & 20 & 7 & 0.8 & 0.4 & 0.20 & 0.03 \\
\hline Managed forest & $\mathbf{4 3}$ & $\mathbf{1 0}$ & $\mathbf{1 . 8}$ & $\mathbf{0 . 6}$ & $\mathbf{0 . 1 8}$ & $\mathbf{0 . 0 5}$ \\
\hline Plantations & 20 & 7 & 0.8 & 0.4 & 0.20 & 0.03 \\
\hline Grazing & $\mathbf{6 6}$ & $\mathbf{2 3}$ & $\mathbf{2 . 1}$ & $\mathbf{1 . 0}$ & $\mathbf{0 . 1 6}$ & $\mathbf{0 . 1 1}$ \\
\hline Broadscale agriculture & 20 & 7 & 0.8 & 0.4 & 0.20 & 0.03 \\
\hline Broadscale annual & $\mathbf{6 6}$ & $\mathbf{2 3}$ & $\mathbf{2 . 1}$ & $\mathbf{1 . 0}$ & $\mathbf{0 . 1 6}$ & $\mathbf{0 . 1 1}$ \\
horticulture & 140 & 10 & 1.6 & 0.7 & 0.28 & 0.07 \\
\hline Broadscale perennial & $\mathbf{1 8 4}$ & $\mathbf{1 2}$ & $\mathbf{2 . 1}$ & $\mathbf{0 . 8}$ & $\mathbf{0 . 2 4}$ & $\mathbf{0 . 2 3}$ \\
horticulture & $\mathbf{1 3 1}$ & 10 & 2.1 & 0.7 & 0.36 & 0.07 \\
\hline Rural Residential & 308 & 21 & 5.3 & 3.4 & 0.93 & 0.34 \\
\hline Suburban & 146 & 12 & 1.6 & 1.1 & 0.13 & 0.10 \\
\hline Dense Urban & 140 & 10 & 1.6 & 0.7 & 0.28 & 0.07 \\
\hline Utilities & $\mathbf{1 3 1}$ & $\mathbf{1 0}$ & $\mathbf{1 . 6}$ & $\mathbf{0 . 7}$ & $\mathbf{0 . 1 3}$ & $\mathbf{0 . 0 4}$ \\
\hline & 140 & 10 & 1.6 & 0.7 & 0.28 & 0.07 \\
\hline $\mathbf{2 7}$ & $\mathbf{2 3}$ & $\mathbf{1 . 3}$ & $\mathbf{0 . 8}$ & $\mathbf{0 . 0 8}$ & $\mathbf{0 . 0 9}$ \\
\hline
\end{tabular}

Four scenarios were run in Source Catchments to compare the effect of hydrological calibration and EMC parameters. These scenarios were the PEST or RRL model with either old or new EMC values. Load data results for gauge 5040525 are shown in Figure 3.

Comparison of simulated and observed loads was made at gauge 5040525. All scenarios predicted higher TSS loads from the catchment than measured, with new EMC values giving higher predictions than the old ones. The closest prediction was PEST model with old EMC values, which estimated loads 95\% higher than observed. The modelled EMC for TSS at this site is approximately $112 \mathrm{mg} / \mathrm{L}$ (calculated from the simulated flow \& load data over the whole study period) while the observed EMC for TSS was $60 \mathrm{mg} / \mathrm{L}$. Hence the model over-predicted TSS loads from this site.

An examination of the contributions from the major landuses supplying the gauge 5040525 helps to clarify the driver to the TSS overestimation. The calculated EMC concentrations (from the flows and loads generated within the model) for grazing, conservation and managed forestry landuses are 156,38 and $59 \mathrm{mg} / 1$ respectively. It is clear from these numbers that the EMC for grazing is contributing the majority of the load and is the principal driver to the overestimation of the TSS loads. This demonstrates the need for local data to calculate EMC values. The EMC value used was from the MLR region, but in fact the EMC at this site was much less than that. This highlights that even though regional data was used to generate the new MLR EMC's, for grazing TSS in the Torrens catchment a more local EMC value is required.

For TN the PEST model with new EMC values gave excellent prediction of loads from this site (within 5\% of the observed total load). The PEST model with the old EMC values predicted lower loads than the new EMC's indicating that the new EMC values give a much more accurate representation of the total loads expected from the landuses. While the PEST model with new EMC values gave excellent prediction of TN loads, it is interesting to note that predicted loads were slightly less than observed in earlier years and slightly 


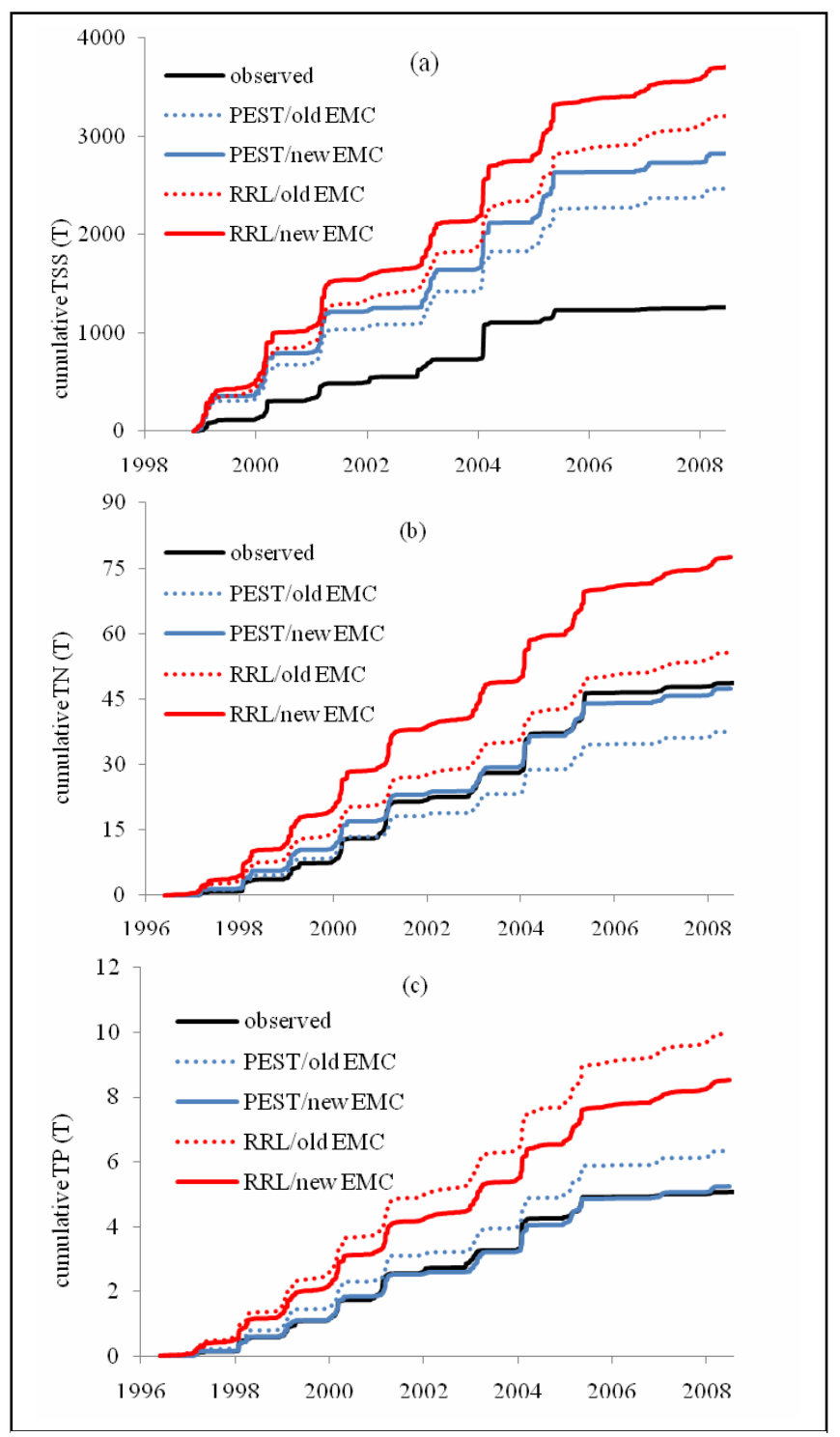

Figure 3. Cumulative load plots of (a) TSS, (b) TN and (c) TP showing relative performance of RRL and PEST models with different EMC/DWC values for stream gauge 5040525 more in later years. This is a limitation of using a single EMC value to represent the constituent generation rate for all years, even in a best-case situation such as this.

For TP the PEST model with new EMC values closely predicted TP loads from this site (within $5 \%$ of the observed total load). The PEST model with old EMC values over estimated the loads and the RRL model predicted higher loads again (around 70-90\% above observed loads).

Limitations of the EMC/DWC approach are evident in these results. Firstly, the averaging approach in these values tends to produce an overestimation of loads in low flow years and underestimation in high flow years or even for years with significant flow event. This is evident even where there is excellent overall prediction, such as with TN and TP. Secondly, the value of local data is highlighted with predicted loads of TSS, where this particular site had lower TSS concentrations than other sites in the region. As discussed above this was most likely due to the EMC for grazing in the Torrens catchment significantly overestimating the sediment generation compared with other areas in the MLR that are dominated by grazing. This may be due variations in topography, soils or even landuse practices. Indeed this requirement for highly localised data, at least for TSS, is not easy to obtain given the difficulty and expense of collecting water quality data from many sites over extended periods. Generally the PEST model gave better load prediction with new EMC

values than with the old ones. This indicates that the new EMC/DWC values are superior as they allow the model to have a greater predictive capacity.

\section{CONCLUSION AND RECOMMENDATIONS}

This work has demonstrated that the systematically PEST calibrated model has enabled the complexity of the Torrens system to be effectively modelled so that more accurate flows are generated. The complexity allowed 3 regions to be calibrated to gauges as compared to 1 upstream gauge which was the previous approach with RRL.

The new EMC/DWC values generated for this study have improved the predictive capacity of this source catchments model especially for TN and TP. The inherent feature of the EMC/DWC constituent generation approach which overall gives a good estimation of loads but taken in isolation tends to over and under predict the low and high extremes in flow conditions respectively. However, given the relative simplicity of the constituent generation approach it is seen as favourable in the absence of more complex and costly process 
driven constituent generations models. In most catchments of the MLR the spatially explicit components required to simulate the processes are not available.

The TSS EMC values for grazing in the Torrens catchment have been defined as a major driver to the overestimation of the TSS loads by the PEST model. It is unclear to the authors why this catchment differs significantly from other grazing catchments in the MLR. The potential for differences in topography, soil types and land management practices have been identified and need to be investigated further.

As a decision support tool for environmental policy makers and natural resource managers this is a useful approach which allows a range of management scenarios to be examined. This updated Source Catchments model is being applied to examine a range of scenarios to provide key inputs and risks into the development of a Water Quality Improvement Plan (WQIP) for the MLR watershed.

\section{ACKNOWLEDGEMENTS}

The authors would like to thank Joel Stewart, Robin Ellis and David Waters for their valuable suggestions during the process of model development and calibration. Special thanks go to Department for Water, SA Water and the Adelaide and Mt Lofty Ranges NRM Board for the assistance with data collection. The support of eWater ltd in the development of this project is greatly appreciated.

\section{REFERENCES}

Barlow, K.B., B. Christy and A. Weeks (2009). Nutrient generation and transport at the catchment scale, In Anderssen, R.S., R.D. Braddock and L.T.H. Newham (eds) 18th World IMACS Congress and MODSIM09 International Congress on Modelling and Simulation. Modelling and Simulation Society of Australia and New Zealand and International Association for Mathematics and Computers in Simulation, July 2009, pp. 1823-1829.

Bradley, J., B. Holmes and S.D. Thomas (2007). Water Quality Snapshot 2001-2002 Historic baseline data for the Mount Lofty Ranges Watershed, South Australian Environment Protection Authority, Adelaide.

Chiew, F.H.S., M.C. Peel and A.W. Western (2002). Application and testing of the simple rainfall-runoff model SIMHYD, In VP Singh \& DK Frevert (eds), Mathematical models of small watershed hydrology and Applications, Water Resources Publication, Colorado, pp.335-367.

Doherty, J. (2010), PEST Model Independent Parameter Estimation User Manual: 5th Edition. Watermark Numerical Computing.

Fleming, N.K., Cox, J.W., He, Y., Thomas, S. and Firzenschaf, J. (2010) Analysis of Total Suspended Sediment and Total Nutrient Concentration data in the Mount Lofty Ranges to derive event mean concentrations, eWater Cooperative Research Centre Technical Report, August 2010. ISBN 978-1921543-32-6

Podger, G. (2004) RRL Rainfall Runoff Library users guide. Cooperative Research Centre for Catchment Hydrology. Available from http://www.toolkit.net.au

Twidale, CR, Tyler, MJ and Web, BP (eds) (1976). Natural history of the Adelaide region, Royal Society of South Australia (Inc), Graphic Services Pty Ltd, South Australia.

WBM (2006) Mt Lofty Ranges Storage Catchments - EMSS to E2 Conversion Report. Document R.B15199.002.00.doc, WBM Proprietary Limited, Queensland, July 2006. 